\title{
Ses Kayıt Stüdyolarında Gürültü Denetimi İçin Uygun Yapı Elemanı Kesit Seçeneklerinin Belirlenmesi
}

\author{
Okan Şimşek $^{1 *}$ \\ 1*Eskişehir Teknik Üniversitesi, Mimarlık ve Tasarım Fakültesi, Mimarlık Bölümü, Eskişehir, Türkiye, (ORCID: 0000-0003-3500-9438), osimsek@eskisehir.edu.tr
} (International Conference on Design, Research and Development (RDCONF) 2021 - 15-18 December 2021)

(DOI: $10.31590 /$ ejosat.1039518)

ATIF/REFERENCE: Şimşek, O. (2021). Ses Kayıt Stiüdyolarında Gürültü Denetimi İçin Uygun Yapı Elemanı Kesit Seçeneklerinin Belirlenmesi. Avrupa Bilim ve Teknoloji Dergisi, (32), 191-196.

$\ddot{O} \mathbf{z}$

Ses kayıt stüdyolarında, iç mekân gürültü seviyesi sınır değerlerinin sağlanması için yapı elemanlarının göstermesi gereken ses yalıtım performansları, kaynak hacmin gürültülülük düzeyi ve alıcı hacmin gürültüye karşı hassasiyetine bağlı olarak belirlenmelidir. Günümüzde yapı içi optimum akustik ortamın sağlanması için, yapı kabuğu ve bölme elemanlarının kesit özelliklerinin belirlenmesinde giderek daha yaygın bir biçimde bilgisayar programlarından yararlanılmaktadır. Bu çalışmanın amacı; ses kayıt stüdyolarında, hacimdeki etkinliği zedelemeyecek akustik ortamların sağlanması için yapı kabuğu ve bölme elemanlarında gürültü denetimine dair hususları içeren mevzuat olan "Binaların Gürültüye Karşı Korunması Hakkında Yönetmelik" çerçevesinde belirtilen yalıtım değerlerini sağlayan, uygun kesit seçeneklerini önermektir. Bunun için Adana DB Ses Kayıt Stüdyosu değerlendirmeye alınarak yapı elemanlarının mevcut performansları belirlenmiştir. Uygun yapı elemanı kesit seçenekleri için, Insul yazılımından faydalanılarak öneriler geliştirilmiştir. Sonuç olarak, ülkemizde yakın zamanda yürürlüğe girmiş olan yönetmelik çerçevesinde, bir ses kayıt stüdyosu yapı elemanı kesit seçeneklerinin belirlenmesine ilişkin bir yöntem önerisi geliştirilmiştir.

Anahtar Kelimeler: Ses kayıt stüdyosu, Gürültü denetimi, Ses yalıtımı.

\section{Determination of Appropriate Structural Component Section Options for Noise Control in Sound Recording Studios}

\begin{abstract}
In sound recording studios, the sound insulation performances of the building elements to ensure the indoor noise level limit values should be determined depending on the noise level of the source volume and the sensitivity of the receiver volume to noise. Nowadays, computer programs are increasingly used to determine the cross-sectional properties of the building envelope and partition elements in order to provide the optimum acoustic environment inside the building. The aim of this study; It is to propose suitable section options that provide the insulation values specified in the 'Regulation on Noise Protection of Builidings', which is the legislation containing the noise control in sound recording studios, building envelope and partition elements. For this, Adana DB Sound Recording Studio was evaluated and the current performances of the building elements were determined. Suggestions have been developed for suitable structural element section options by using Insul software. As a result, a method proposal has been developed for the determination of a sound recording studio structural element section options within the framework of the regulation that has recently entered into force in our country.
\end{abstract}

Keywords: Sound recording studio, Noise control, Sound insulation.

*Sorumlu Yazar: osimsek@eskisehir.edu.tr 


\section{Giriş}

Gürültü, işitsel konfor açısından istenmeyen, kullanıcıları kapalı ve açık alanlarda rahatsız eden bir çevre problemi olarak tanımlanmaktadır. $\mathrm{Bu}$ problem yapı tasarım aşamasında mekânlardan uzaklaştırılmalı ya da kontrol altına alınmalıdır(Yılmaz Demirkale, 2007)(Kurra, 2009). Gürültüye maruz kalan kullanıcılarda fizyolojik ve psikolojik problemlere yol açtığı bilinmektedir. Özellikle plansız kentleşmenin yoğun olduğu bölgelerde gürültü, toplum sağlığını ve huzurunu olumsuz etkileyen nedenler arasındadır. Bu sebeplerle gürültü, kontrol altına alınarak olumsuz etkilerinin en aza indirilmesi gereken en önemli çevre problemlerinden biri olarak karşımıza çıkmaktadır(Monteiro, Machimbarrena, Tarrero, \& Smith, 2017)(Hongisto, Mäkilä, \& Suokas, 2015)(Pääkkönen et al., 2015)(Jagniatinskis, Mickaitis, \& Fiks, 2013)(Garg, Kumar, \& Maji, 2013).

$\mathrm{Bu}$ bağlamda yapılarda gürültü denetimine ilişkin düzenlemeleri kapsayan "Binaların Gürültüye Karşı Korunması Hakkında Yönetmelik" 31 Mayıs 2017 Tarihinde 30082 sayılı Resmî Gazete 'de yayımlanmış ve 31 Mayıs 2018 tarihinde yürürlüğe girmiştir(Çevre ve Şehircilik Bakanlığı, 2017). Bu yönetmelik ile her türlü yapı, bina, tesis ve işletmenin işletimi ve kullanımı esnasında insanların maruz kalacağı, her türlü gürültünün, kişilerin, beden ve ruh sağlığına olumsuz etkilerini en aza indirecek iyi işitme ve algılama koşullarının sağlanması için, tasarım, yapım, kullanım, bakım ve işletim bakımından uyulacak kurallar tanımlanmıştır(Bayazıt, Kurra, Özbilen, \& Şentop, 2018).

Bir yapı elemanının ses geçiş kaybı değerini bulmak için literatürde bazı hesap yöntemleri bulunmaktadır. Ancak dolaylı geçişler, hacim büyüklüğü ve hacimlerin toplam ses yutuculuğu parametrelerinin de yapı elemanının performansında incelenebildiği; programlar ve hesap yöntemleri ile sonuçlar daha hızlı elde edilmekte ve gerçeğe daha da yaklaşabilmektedir. Bu çalışmada; yönetmelik çerçevesinden belirtilen ses geçiş kaybı değerleri tespit edilerek ses kayıt stüdyosu yapı kabuğu ve bölme elemanlarının sağlaması gereken yalıtım değerleri ile buna uygun kesit seçenekleri Adana DB ses kayıt stüdyosu üzerinden önerilmektedir. Bunun için TS EN 12354-1,3 (September, 2017) standartlarını referans alan, INSUL yapı akustiği hesaplama yazılımından yararlanılmıştır.

\section{Materyal ve Metot}

$\mathrm{Bu}$ çalışma kapsamında Adana DB Ses Kayıt Stüdyosu incelenerek yerinde gözlemler yapılmış ve rölövesi alınmıştır (Şekil 1, 2). Binaların Gürültüye Karşı Korunması Hakkında Yönetmelik kapsamında yeni tasarlanacak yapılar için en az $\mathrm{C}$ akustik performans sınıfı sağlanması şartı dikkate alınarak $\mathrm{C}$ akustik performans sınıfı hedeflenmiştir. $\mathrm{Bu}$ doğrultuda stüdyo içerisinde gerçekleştirilecek eylemlere uygun akustik koşulların oluşmasına imkan verecek yapı elemanı kesit seçenekleri önerilecektir.
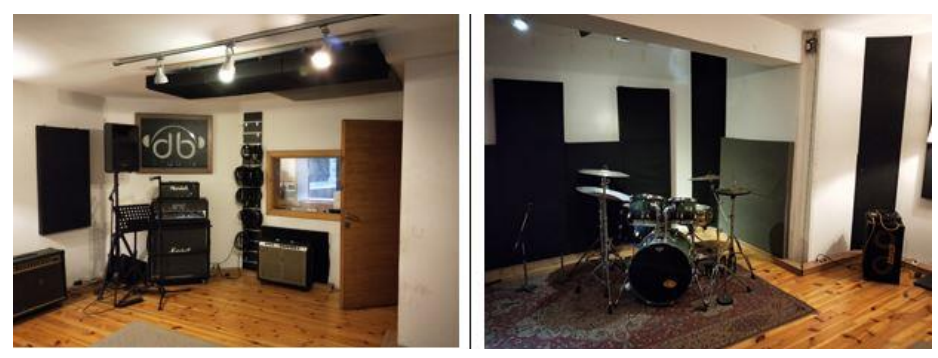

Şekil 1. Adana DB Ses Kayıt Stüdyosu Fotoğrafları
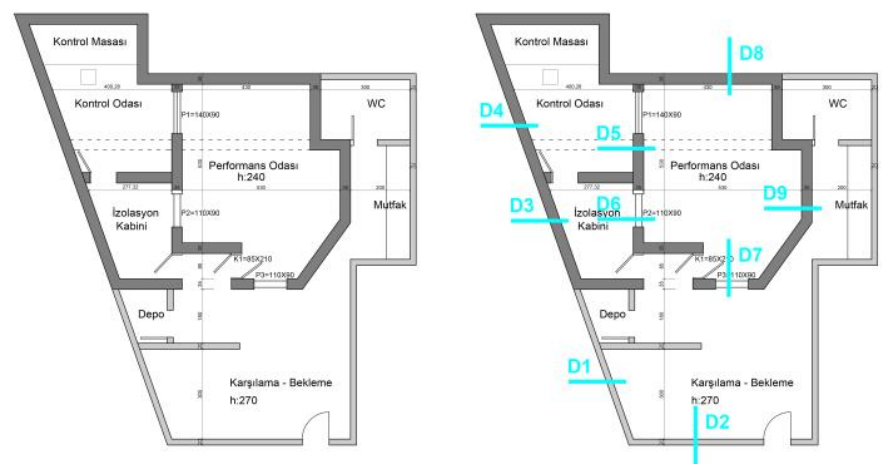

Şekil 2. Adana DB Ses Kayıt Stüdyosu Planı ve yapı elemanı isimleri

Örnek ses kayıt stüdyosu yapı elemanlarının ses geçiş kaybı değerlerini hesaplamak için yapı elemanlarının ses geçiş kaybı değerlerini TS EN 12354-1,3 [1] numaralı standartları referans alarak hesaplayan INSUL ses geçiş kaybı hesaplama programı kullanılmıştır (Şekil 3).

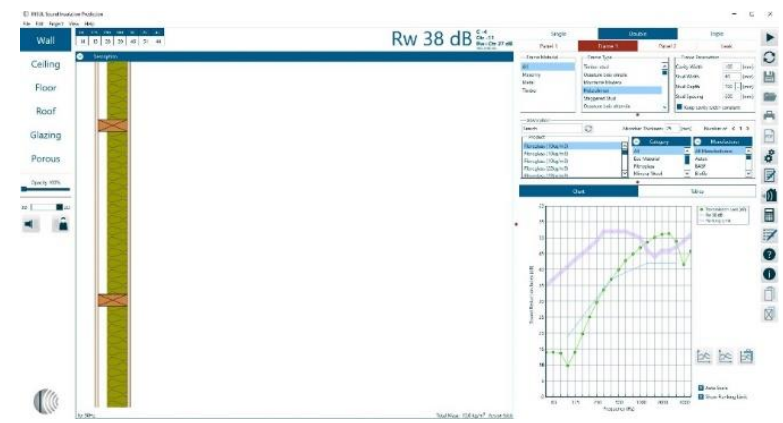

Şekil 3. INSUL Programı Arayüzü

\subsection{Kabuller}

Çalışma kapsamında ses kayıt stüdyosu yapı dışı ses kaynağı için trafik gürültüsü kabulü yapılmış olup ses kayıt stüdyosu yapı kabuğu üzerine $75 \mathrm{~dB}$ ses etki ettiği kabul edilmiştir.

Yapı elemanlarının ses geçiş kaybı performansı için Binaların Gürültüye Karşı Korunması Hakkında Yönetmelik çerçevesinde belirlenen $\mathrm{C}$ akustik performans sinıfi hedeflenerek, DnT,A,tr = $\mathrm{D} 2 \mathrm{~m}, \mathrm{nT}, \mathrm{w}+\mathrm{Ctr}, 100-3150 \geq 75 \mathrm{~dB}-22 \mathrm{~dB}$ formülü kullanılarak yapı kabuğu için yeterli yalıtım DnT,A,tr $\geq 53 \mathrm{~dB}$ olarak belirlenmiştir.

Ses kayıt stüdyosu ara duvarları için ise komşu hacimler arasında sağlanacak en düşük hava doğuşlu ses geçiş kaybı değeri için Binaların Gürültüye Karşı Korunması Hakkında Yönetmelik Tablo 3.4.'de ki tabloda yer almayan bir komşuluk ilişkisi söz konusudur. $\mathrm{Bu}$ yüzden Yönetmelik EK-2 Tablo 2.1'den yararlanıldığında ses kayıt stüdyoları alıcı hacim durumunda gürültüye karşı çok hassas hacim kategorisinde yer alırken stüdyonun diğer bölümleri yüksek seviyeli gürültü kaynağı olarak 
kabul edilmiştir. Komşuluk durumu değerlendirildiğinde kaynak hacim yüksek seviyeli gürültü kaynağı, alıcı hacim ses kayıt stüdyosu performans ve kayıt odaları olarak belirlendiğinde; DnT,A $=$ DnT,w + C, 100-3150 $\geq 58 \mathrm{~dB}$ hesabı yapılmış ve bölme elemanları için ses geçiş kaybı değeri DnT,A $\geq 58 \mathrm{~dB}$ olarak belirlenmiştir.

\section{Araştırma Sonuçları ve Tartışma}

Binaların Gürültüye Karşı Korunması Hakkında Yönetmelik kapsamında yeni inşa edilecek yapıların ses geçiş kaybı düzeylerini tespit etme sürecinde öncelikle gürültü kaynağının bulunduğu kaynak hacimdeki ses basınç düzeyinin belirlenmesi gerekmektedir. Alıcı hacme ulaşan ses, dış mekândan alıcıya ulaşan ses olabileceği gibi bitişik hacimden gelen seste olabilir. İlk olarak alıcı hacmi etkileyen gürültü kaynakları ve bunların düzeyleri tespit edilmelidir. İkinci olarak ise yapı kabuğunun ve bölme elemanlarının sağlaması gereken ses geçiş kaybı değerleri hesaplanmalıdır. Yapı kabuğunun sağlaması gereken ses geçiş kaybı değeri belirlenmeden önce mekanların gürültüye duyarlılık düzeyleri yönetmelikteki EK-2 Tablo 2.1'den faydalanılarak belirlenmesi gerekmektedir. Daha sonra yönetmelik EK-3 Tablo 3.1'den faydalanılarak yap1 kabuğunun sağlaması gereken ses geçiş kaybı değeri bulunacaktır.

Ses kayıt stüdyoları için yönetmelikteki EK-2 Tablo 2,1'de yer alan tabloya göre ses kayıt stüdyosu alıcı hacim iken gürültüye karşı çok hassas yapı grubunda yer almaktadır. Daha sonra EK-3 Tablo 3.1'den faydalanılarak ses kayıt stüdyoları için yapı kabuğu ses geçiş kaybı değeri, A ağırlıklı uzun süreli ortalama ses düzeylerinden elde edilen ve diş mekan gürültülerinin seviyesini gösteren Gündüz-akşam-gece düzeyinden (Lgag veya Lden) 22 dB çıkarılarak belirlenecektir.

Bölme elemanlarının sağlaması gereken ses geçiş kaybı değerinin hesaplanmasinda ise EK-3 Tablo 3.4'te bulunan komşuluk ilişkilerine göre bölme elemanlarından istenen en düşük ses geçiş kaybı değeri kullanılacaktır. Tablo 3.4'te bulunmayan bir komşuluk ilişkisi varsa, önce mekanların gürültülülük ve gürültüye duyarlılık düzeyleri EK-2 Tablo 2.1'den faydalanılarak tespit edilecektir. Hacimlerin gürültülülük ve duyarlılık seviyeleri tespit edildikten sonra yönetmelik EK-3 Tablo 3.2 kullanılarak sağlanması gereken ses geçiş kaybı değeri belirlenecektir.

Ses kayıt stüdyoları için yönetmelikteki EK-3 Tablo 3.4'de yer alan tabloya göre ses kayıt stüdyosu alıcı olması durumunda tabloda belirtilmeyen bir komşuluk ilişkisi söz konusudur. Yönetmelik EK-2 Tablo 2.1'den yararlanıldığında ses kayıt stüdyoları alıcı hacim iken gürültüye karşı çok hassas yap1 grubunda yer alırken kaynak olması durumunda ise yüksek düzeyli gürültü ürettiği belirlenmiştir. Daha sonra Yönetmelik EK-3 Tablo 3.2 'de C akustik performans sınıfı için istenen bölme elemanı ses geçiş kaybı değeri $58 \mathrm{~dB}$ olarak tespit edilmiştir.

\subsection{Ses Kayıt Stüdyosunun Mevcut Gürültü Denetimi Tespiti}

Mevcut durumda Adana DB Ses Kayıt Stüdyosu duvar elemanı için tuğla kesitler kullanılmıştır. Performans odası ve kontrol odası için ise tuğla üzerine hava boşluğu bırakılarak mineral yünü ve alçı levhalar kullanılmıştır. Adana DB Ses Kayıt Stüdyosu'nda tespit edilen kesit detay çizimleri Tablo 1'de yer almaktadır.
Tablo 1. Adana Stüdyo DB Ses Kayıt Stüdyosu Mevcut Detaylarl

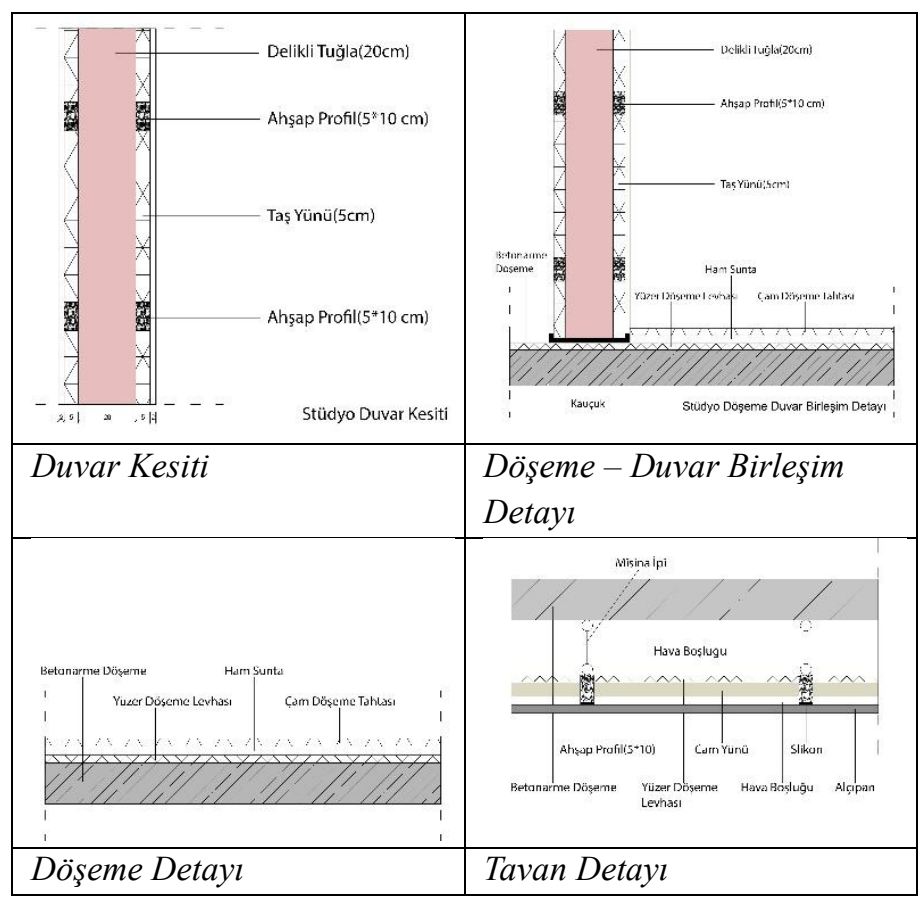

Tablo 2'de ise ses kayıt stüdyosu için Binaların Gürültüye Karşı Korunması Hakkındaki Yönetmelik’te belirtilen C akustik performans sınıfı yapı olabilmesi için duvarların sağlaması gereken ses geçiş kaybı değerleri verilmiştir.

Tablo 2. Yapının Duvarlarına Göre Sağlanması Gereken Ses Geçiş Kaybı Değerleri

\begin{tabular}{|l|c|c|c|}
\hline $\begin{array}{l}\text { Duvar } \\
\text { Adı }\end{array}$ & $\begin{array}{c}\text { Kaynak } \\
\text { Hacim }\end{array}$ & Alıcı Hacim & $\begin{array}{c}\text { Sağlanması } \\
\text { Gereken Ses } \\
\text { Geçiş Kaybı } \\
\text { Değeri }\end{array}$ \\
\hline$D 1$ & Dış Mekan & Bekleme Alanı & 53 \\
\hline$D 2$ & Dış Mekan & Bekleme Alanı & $53-14=39$ \\
\hline$D 3$ & Diş Mekan & İzolasyon Kabini & 53 \\
\hline$D 4$ & Diş Mekan & Kontrol Odası & 53 \\
\hline$D 5$ & $\begin{array}{c}\text { Kontrol } \\
\text { Odası }\end{array}$ & Performans Odası & 58 \\
\hline$D 6$ & $\begin{array}{c}\text { İzolasyon } \\
\text { Kabini }\end{array}$ & Performans Odası & 58 \\
\hline$D 7$ & $\begin{array}{c}\text { Bekleme } \\
\text { Alanı }\end{array}$ & Performans Odası & 58 \\
\hline$D 8$ & Diş Mekan & Performans Odası & 58 \\
\hline$D 9$ & Mutfak & Performans Odası & 58 \\
\hline
\end{tabular}

Mevcut durumda Adana Stüdyo DB Ses Kayıt Stüdyosu yapı elemanlarının ses geçiş kaybı değerleri hesaplanmıştır (Tablo 3). Ses kayıt stüdyosunun yapı kabuğunda kullanılan 200mm düşey delikli tuğla duvar yönetmelik kapsamında $\mathrm{C}$ akustik performans sınıfı için istenen ses geçiş kaybı düzeyini sağlayamamıştır. 
Tablo 3. Ses Kayıt Stüdyo Mevcut Yapı Elemanlarının Performansları

\begin{tabular}{|c|c|c|c|c|c|}
\hline & Kesit1 & Yapı Elemanı 1 & Kesit2 & Yapı Elemanı 2 & Sonuc \\
\hline D1 & & $\begin{array}{c}-10 \mathrm{~mm} \text { alçı sıva } \\
-200 \mathrm{~mm} \text { düşey delikli tuğla duvar } \\
-10 \mathrm{~mm} \text { alçı sıva }\end{array}$ & - & - & $\begin{array}{l}32,81 \leq 53 \text { olduğu } \\
\text { için uygun değil. }\end{array}$ \\
\hline D2 & & $\begin{array}{c}-10 \mathrm{~mm} \text { alçı sıva } \\
-200 \mathrm{~mm} \text { gazbeton blok duvar } \\
-10 \mathrm{~mm} \text { alçı sıva }\end{array}$ & T. & $\begin{array}{c}\text { Kapı } \\
-10 \mathrm{~mm} \text { ahşap levha } \\
-40 \mathrm{~mm} \text { cam yünü } \\
-10 \mathrm{~mm} \text { ahşap levha }\end{array}$ & $\begin{array}{l}36,04 \leq 39 \text { olduğu } \\
\text { için uygun değil. }\end{array}$ \\
\hline D3 & & $\begin{array}{c}-20 \mathrm{~mm} \text { alçı panel } \\
-50 \mathrm{~mm} \text { ahşap latalar } \\
-50 \mathrm{~mm} \text { mineral yünü } \\
-200 \mathrm{~mm} \text { delikli tuğla duvar } \\
-50 \mathrm{~mm} \text { ahşap latalar } \\
-50 \mathrm{~mm} \text { mineral yünü } \\
-20 \mathrm{~mm} \text { alçı panel }\end{array}$ & - & - & $\begin{array}{l}48,6 \leq 53 \text { olduğu } \\
\text { için uygun değil. }\end{array}$ \\
\hline D4 & & $\begin{array}{c}-20 \mathrm{~mm} \text { alçı panel } \\
-50 \mathrm{~mm} \text { ahşap latalar } \\
-50 \mathrm{~mm} \text { mineral yünü } \\
-200 \mathrm{~mm} \text { delikli tuğla duvar } \\
-50 \mathrm{~mm} \text { ahşap latalar } \\
-50 \mathrm{~mm} \text { mineral yünü } \\
-20 \mathrm{~mm} \text { alçı panel }\end{array}$ & - & - & $\begin{array}{l}50,4 \leq 53 \text { olduğu } \\
\text { için uygun değil. }\end{array}$ \\
\hline D5 & & $\begin{array}{c}-20 \mathrm{~mm} \text { alçı panel } \\
-50 \mathrm{~mm} \text { ahşap latalar } \\
-50 \mathrm{~mm} \text { mineral yünü } \\
-200 \mathrm{~mm} \text { delikli tuğla duvar } \\
-50 \mathrm{~mm} \text { ahşap latalar } \\
-50 \mathrm{~mm} \text { mineral yünü } \\
-20 \mathrm{~mm} \text { alçı panel } \\
\end{array}$ & & $\begin{array}{c}-6 \mathrm{~mm} \text { cam } \\
-100 \mathrm{~mm} \text { hava boşluğu } \\
-6 \mathrm{~mm} \text { cam } \\
-100 \mathrm{~mm} \text { hava boşluğu } \\
-6 \mathrm{~mm} \text { cam }\end{array}$ & $\begin{array}{l}58,12 \geq 58 \text { olduğu } \\
\text { için uygun. }\end{array}$ \\
\hline D6 & & $\begin{array}{c}-20 \mathrm{~mm} \text { alçı panel } \\
-50 \mathrm{~mm} \text { ahşap latalar } \\
-50 \mathrm{~mm} \text { mineral yünü } \\
-200 \mathrm{~mm} \text { delikli tuğla duvar } \\
-50 \mathrm{~mm} \text { ahşap latalar } \\
-50 \mathrm{~mm} \text { mineral yünü } \\
-20 \mathrm{~mm} \text { alçı panel }\end{array}$ & & $\begin{array}{c}-8 \mathrm{~mm} \text { lamine cam } \\
-100 \mathrm{~mm} \text { hava boşluğu } \\
-8 \mathrm{~mm} \text { lamine cam }\end{array}$ & $\begin{array}{l}58,18 \geq 58 \text { olduğu } \\
\text { için uygun. }\end{array}$ \\
\hline D7 & & $\begin{array}{c}-20 \mathrm{~mm} \text { alçı panel } \\
-50 \mathrm{~mm} \text { ahşap latalar } \\
-50 \mathrm{~mm} \text { mineral yünü } \\
-200 \mathrm{~mm} \text { delikli tuğla duvar } \\
-50 \mathrm{~mm} \text { ahşap latalar } \\
-50 \mathrm{~mm} \text { mineral yünü } \\
20 \mathrm{~mm} \text { alçı panel }\end{array}$ & & $\begin{array}{l}-8 \mathrm{~mm} \text { lamine cam } \\
-100 \mathrm{~mm} \text { hava boşluğu } \\
-8 \mathrm{~mm} \text { lamine cam }\end{array}$ & $\begin{array}{l}58,6 \geq 58 \text { olduğu } \\
\text { için uygun. }\end{array}$ \\
\hline$D 8$ & & $\begin{array}{c}-20 \mathrm{~mm} \text { alçı panel } \\
-50 \mathrm{~mm} \text { ahşap latalar } \\
-50 \mathrm{~mm} \text { mineral yünü } \\
-200 \mathrm{~mm} \text { delikli tuğla duvar } \\
-50 \mathrm{~mm} \text { ahşap latalar } \\
-50 \mathrm{~mm} \text { mineral yünü } \\
-20 \mathrm{~mm} \text { alçı panel }\end{array}$ & - & - & $\begin{array}{l}48,3 \leq 53 \text { olduğu } \\
\text { için uygun değil. }\end{array}$ \\
\hline D9 & & $\begin{array}{c}-20 \mathrm{~mm} \text { alçı panel } \\
-50 \mathrm{~mm} \text { ahşap latalar } \\
-50 \mathrm{~mm} \text { mineral yünü } \\
-200 \mathrm{~mm} \text { delikli tuğla duvar } \\
-50 \mathrm{~mm} \text { ahşap latalar } \\
-50 \mathrm{~mm} \text { mineral yünü } \\
-20 \mathrm{~mm} \text { alçı panel }\end{array}$ & - & - & $\begin{array}{l}58,4 \geq 58 \text { olduğu } \\
\text { için uygun. }\end{array}$ \\
\hline
\end{tabular}


Yine ses kayıt stüdyosunun yapı kabuğunda kullanılan $200 \mathrm{~mm}$ düşey delikli tuğla duvar (iki yanı $50 \mathrm{~mm}$ ahşap latalar üzerinde yükseltilmiş arası mineral yünü dolgulu $20 \mathrm{~mm}$ alçı levhalar) yönetmelik kapsamında $\mathrm{C}$ akustik performans sınıfı için istenen ses geçiş kaybı düzeyini sağlayamamıştır.

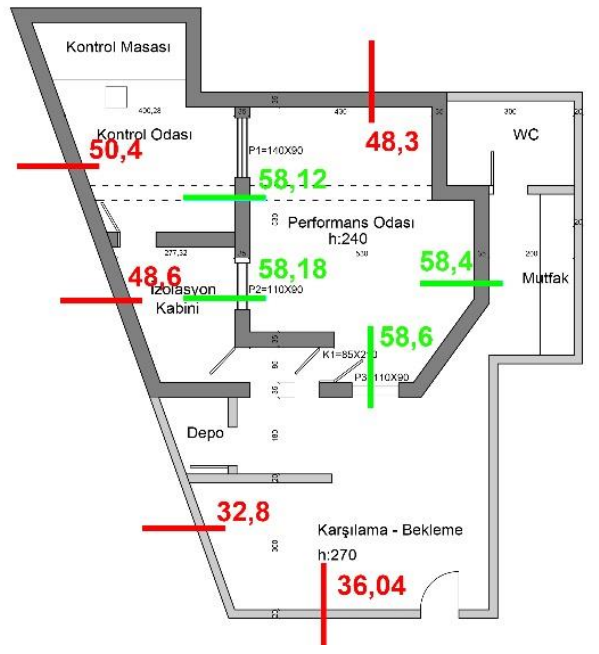

Şekil 4. Adana DB Ses Kayıt Stüdyosu Yapı Elemanlarının Sağladığı Ses Geçiş Kayıpları
Ancak ses kayıt stüdyosunun performans odasını stüdyonun diğer birimlerinden ayıran bölücü duvarlar yönetmelik kapsamında istenen ses geçiş kaybı düzeylerini sağlamıştır. Sonuç olarak tüm yapı kabuğu ve bölme elemanlarının ses geçiş kaybı performansları Şekil 4'de gösterilmektedir.

\subsection{Ses Kayıt Stüdyosunun Gürültü Denetimi için Uygun Yapı Elemanı Seçeneklerinin Belirlenmesi}

Mevcut durumda Adana DB Ses Kayıt Stüdyosu yapı elemanlarının ses geçiş kaybı değerleri önceki bölümde tespit edilmiştir. Bu bölümde ise Binaların Gürültüye Karşı Korunması Hakkında Yönetmelik çerçevesinde amaçlanan ses geçiş kaybı değerlerinin sağlanabilmesi için öneriler getirilecektir(Tablo 4).

D1 için geliştirilen öneride, $200 \mathrm{~mm}$ delikli tuğla $\left(600 \mathrm{~kg} / \mathrm{m}^{3}\right)$ yerine $200 \mathrm{~mm}$ dolu tuğla $\left(1600 \mathrm{~kg} / \mathrm{m}^{3}\right)$ duvar önerilmiştir. $\mathrm{Bu}$ öneriyle birlikte yapı kabuğunda istenen yalıtım değeri elde edilmiştir.

D2 için geliştirilen öneride, iki yanı $10 \mathrm{~mm}$ alçı sıvalı $200 \mathrm{~mm}$ delikli tuğla bileșik cidarının üzerinde yer alan kapı, bileşik cidarın ses geçiş kaybını büyük ölçüde azaltmaktadır. Bileşik cidarın zayıf elemanı olan kapı için öneri olarak $20 \mathrm{~mm}$ iki ahşap levha arasındaki cam yünü $4 \mathrm{~mm}$ yerine $8 \mathrm{~mm}$ kullanılarak yönetmelikte belirtilen ses geçiş kaybı değeri sağlanmıştır.

\begin{tabular}{|c|c|c|c|c|c|}
\hline & Kesit1 & Yapı Elemanı 1 & Kesit2 & Yapı Elemanı 2 & SONUÇ \\
\hline D1 & & $\begin{array}{c}-10 \mathrm{~mm} \text { alçı sıva } \\
-200 \mathrm{~mm} \text { dolu tuğla duvar } \\
-10 \mathrm{~mm} \text { alçı sıva }\end{array}$ & - & - & $\begin{array}{c}53,8 \geq 53 \text { olduğu için } \\
\text { uygun. }\end{array}$ \\
\hline D2 & & $\begin{array}{c}-10 \mathrm{~mm} \text { alçı sıva } \\
-200 \mathrm{~mm} \text { gazbeton blok duvar } \\
-10 \mathrm{~mm} \text { alçı sıva }\end{array}$ & tha & $\begin{array}{c}\text { Kapı } \\
\text {-20mm ahşap levha } \\
-160 \mathrm{~mm} \text { mineral yünü } \\
-20 \mathrm{~mm} \text { ahşap levha }\end{array}$ & $\begin{array}{c}39,36 \geq 39 \text { olduğu için } \\
\text { uygun. }\end{array}$ \\
\hline D3 & & $\begin{array}{c}-20 \mathrm{~mm} \text { alçı panel } \\
-100 \mathrm{~mm} \text { ahşap latalar } \\
-50 \mathrm{~mm} \text { mineral yünü } \\
-200 \mathrm{~mm} \text { dolu tuğla duvar } \\
-100 \mathrm{~mm} \text { ahşap latalar } \\
-50 \mathrm{~mm} \text { mineral yünü } \\
-20 \mathrm{~mm} \text { alçı panel }\end{array}$ & - & - & $\begin{array}{c}63,6 \geq 53 \text { olduğu için } \\
\text { uygun. }\end{array}$ \\
\hline$D 4$ & & $\begin{array}{c}-20 \mathrm{~mm} \text { alçı panel } \\
-100 \mathrm{~mm} \text { ahşap latalar } \\
-50 \mathrm{~mm} \text { mineral yünü } \\
-200 \mathrm{~mm} \text { dolu tuğla duvar } \\
-100 \mathrm{~mm} \text { ahşap latalar } \\
-50 \mathrm{~mm} \text { mineral yünü } \\
-20 \mathrm{~mm} \text { alçı panel }\end{array}$ & - & - & $\begin{array}{c}65,4 \geq 53 \text { olduğu için } \\
\text { uygun. }\end{array}$ \\
\hline$D 8$ & & $\begin{array}{c}-20 \mathrm{~mm} \text { alçı panel } \\
-100 \mathrm{~mm} \text { ahşap latalar } \\
-50 \mathrm{~mm} \text { mineral yünü } \\
-200 \mathrm{~mm} \text { dolu tuğla duvar } \\
-100 \mathrm{~mm} \text { ahşap latalar } \\
-50 \mathrm{~mm} \text { mineral yünü } \\
-20 \mathrm{~mm} \text { alçı panel }\end{array}$ & - & - & $\begin{array}{c}63,3 \geq 53 \text { olduğu için } \\
\text { uygun. }\end{array}$ \\
\hline
\end{tabular}


D3, D4 ve D8 için geliştirilen önerilerde ise $200 \mathrm{~mm}$ delikli tuğla $\left(600 \mathrm{~kg} / \mathrm{m}^{3}\right)$ yerine $200 \mathrm{~mm}$ dolu tuğla $\left(1600 \mathrm{~kg} / \mathrm{m}^{3}\right)$ duvar önerilmiştir. $200 \mathrm{~mm}$ dolu tuğla duvar, iki yanı $100 \mathrm{~mm}$ ahşap latalar üzerinde yükseltilmiş arası mineral yünü dolgulu $20 \mathrm{~mm}$ alçı levhalar kullanılmıştır. Mevcut durumdaki kesite göre hava boşlukları $50 \mathrm{~mm}$ arttırılmıştır. Dolu tuğla duvar ile alçı levhalar arasında kalan $100 \mathrm{~mm}$ alana $50 \mathrm{~mm}$ mineral yünü eklenmiştir. $\mathrm{Bu}$ durumda yönetmelikte belirtilen ses geçiş kaybı değeri sağlanmıştır (Şekil 5).

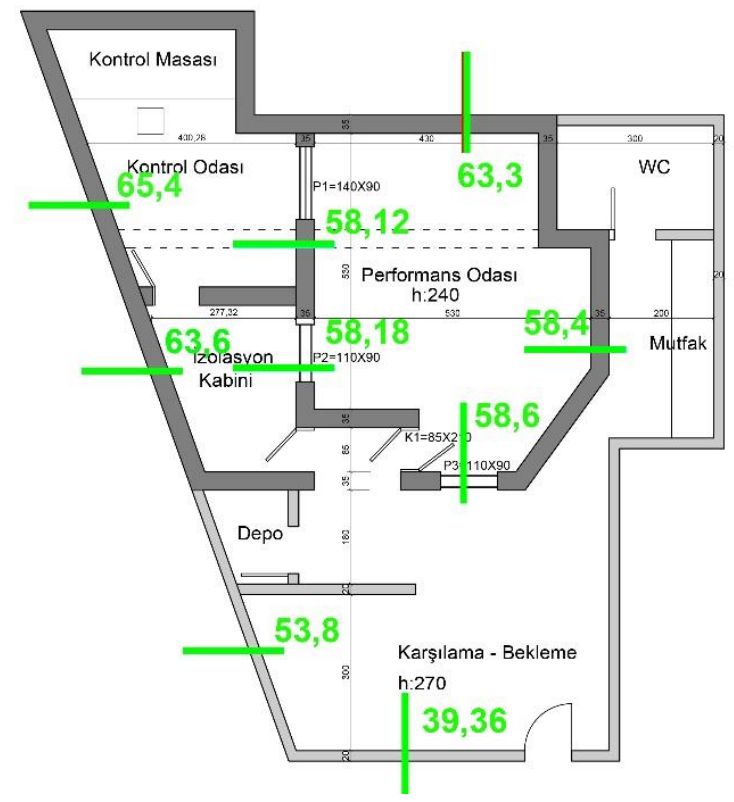

Şekil 5. Adana DB Ses Kayıt Stüdyosu'nun Yapı Elemanlarının Iyileştirme Sonrası Performansları

\section{Sonuç}

Bu çalışmada, ses kayıt stüdyosu hacimlerinde, gürültü açısından uygun iç mekân akustik ortamların oluşması için "Binaların Gürültüye Karşı Korunması Hakkında Yönetmelik" çerçevesinde yapı elemanları için belirtilen ses geçiş kaybı değerleri incelenmiştir. Daha sonra, Adana DB Ses Kayıt Stüdyosu örneği üzerinden mevcut yapı kabuğu ve bölme elemanlarının ses geçiş kaybı performansları tespit edilerek yönetmelikteki sınır düzeyler ile karşılaştırılmıştır. Yönetmelik kapsamında ses kayıt stüdyoları için önerilen sınır düzeyleri sağlayamayan yapı kabuğu ve bölme elemanları için öneriler getirilerek ses kayıt stüdyolarında gürültü açısından uygun iç mekân akustik ortamların oluşması için yapı elemanlarının ses geçiş kaybı değerlerini sağlaması amaçlanmıştır. Bu doğrultuda yapı elemanlarının ses geçiş kaybı performansı, TS EN 12354-1,3 standartlarını referans alan, INSUL yapı akustiği hesaplama yazılımı kullanılarak gerçekleştirilmiştir.

$\mathrm{Bu}$ çalışmada örnek bir ses kayıt stüdyosu ele alınarak ses kayıt stüdyolarında sıklıkla tercih edilen yapı elemanlarının ses geçiş kaybı performansları Binaların Gürültüye Karşı Korunması Hakkında Yönetmelik üzerinden detaylı olarak incelenmiştir. Sonraki aşamada mevcut yap1 elemanları üzerinden öneriler geliştirilerek yapı sektöründe kullanımı yaygın olan mineral yünü, alçı panel levha, çeşitli özelliklere sahip camlar ve kapı çeşitleri gibi iyileştirmelerle uygulanabilir öneriler getirilerek mevcut durumun iyileştirilmesi yapılmıştır. Sonraki çalışmalarda ise ses kayıt stüdyoları için yapı elemanlarının ses geçiş kaybı analizleri ve geliştirilecek iyileştirme çalışmaları çeşitlendirilerek, mevcut ya da yeni tasarlanacak olan ses kayıt stüdyolarının ses geçiş kaybı performansları açısından uygun yap1 elemanlarının belirlenmesine yol gösterici olması hedeflenmektedir.

\section{Kaynakça}

Bayazit, N. T., Kurra, S., Özbilen, B. Ş., \& Şentop, A. (2018). Binaların Gürültüye Karşı Korunması Yönetmeliği Açılklama ve Uygulama Kllavuzu. Retrieved from

https://www.izoder.org.tr/dosyalar/binalarin-gurultuye-karsikorunmasi-yonetmeligi-aciklama-ve-uygulama-klavuzu.pdf

Çevre ve Şehircilik Bakanlığı. Binaların Gürültüye Karşı Korunması Hakkında Yönetmelik. , (2017). Turkiye: Resmi Gazete.

Garg, N., Kumar, A., \& Maji, S. (2013). Significance and implications of airborne sound insulation criteria in building elements for traffic noise abatement. Applied Acoustics. https://doi.org/10.1016/j.apacoust.2013.05.012

Hongisto, V., Mäkilä, M., \& Suokas, M. (2015). Satisfaction with sound insulation in residential dwellings - The effect of wall construction. Building and Environment. https://doi.org/10.1016/j.buildenv.2014.12.010

Jagniatinskis, A., Mickaitis, M., \& Fiks, B. (2013). Development classification scheme for evaluation dwellings sound insulation performance in Lithuania. Procedia Engineering. https://doi.org/10.1016/j.proeng.2013.04.057

Kurra, S. (2009). Çevre gürültüsü ve yönetimi I-II-III. İstanbul: Bahçeşehir Üniversitesi Yayınları.

Monteiro, C., Machimbarrena, M., Tarrero, A. I., \& Smith, R. S. (2017). Translation between existing and proposed harmonized airborne sound insulation descriptors: A statistical approach based on in-situ measurements. Applied Acoustics, 116, 94-106. https://doi.org/10.1016/j.apacoust.2016.09.017

Pääkkönen, R., Vehviläinen, T., Jokitulppo, J., Niemi, O., Nenonen, S., \& Vinha, J. (2015). Acoustics and new learning environment - A case study. Applied Acoustics, 100, 74-78. https://doi.org/10.1016/j.apacoust.2015.07.001

September, I. C. (2017). BS EN ISO 12354-1 : 2017 BSI Standards Publication Building acoustics - Estimation of acoustic performance of buildings from the performance of elements.

Yılmaz Demirkale, S. (2007). Çevre ve yapı akustiği. Birsen Yayınevi. 